\title{
Da globalização inevitável à internacionalização desejável ${ }^{1}$
}

Anna Carolina Lo Bianco

Foi com grande prazer que aceitei o convite do CONPSI para estar nesta mesa-redonda hoje. Não só pela oportunidade de interlocução com os colegas sobre o tema da internacionalização, mas sobretudo por podermos retomar o debate (já agora com alguns avanços) que tivemos em Bento Gonçalves por ocasião do seminário "Horizontes da PG em Psicologia” organizado pela Coordenação de Área na CAPES - Coordenação de Aperfeiçoamento de Pessoal de Nível Superior, e pela ANPEPP - Associação Nacional de Pesquisa e Pós-graduação em Psicologia.

Aqui interessa-me especialmente fazer uma reflexão sobre o contexto mais amplo em que está inserida a questão da internacionalização, na história do país e na rede de conhecimentos em que a psicologia toma lugar. Mas quando eu falo que minha intenção é fazer uma reflexão não é sem consideração pelas consequências práticas (eu diria mesmo positivas) que a maneira como pensamos a internacionalização terá sobre a política de avaliação e sobre a consequente distribuição de recursos que ela determina.

1. Texto falado no $6^{\circ}$ Congresso Norte-Nordeste de Psicologia - CONPSI, realizado em Belém (PA), maio de 2009, na mesa-redonda “Impacto da Internacionalização na Pós-graduação em Psicologia”. 
Falar da internacionalização da psicologia no Brasil, como aliás falar de internacionalização de quase qualquer disciplina entre nós, é, de certa maneira, redundante. A psicologia, como de resto quase todas as disciplinas dos programas universitários, já nasce internacionalizada, na medida em que o saber que primeiro nos chega vem dos países centrais, quase sempre europeus e posteriormente da América do Norte.

Os trabalhos de história da psicologia no Brasil, que hoje em dia são bastante desenvolvidos, mostram a complexa teia em que se constitui a psicologia brasileira, as linhas de força que entre os saberes médicos e pedagógicos levam à instituição de cada laboratório ou de cada campo de estudo, até a formação dos primeiros cursos universitários de psicologia no país. Os estudos, com enorme frequência, remetem a um pesquisador ou a um profissional estrangeiro que chega ao Brasil representando um pensamento vindo dos países, em sua maioria europeus. Tornam-se, pois, responsáveis pela inauguração entre nós de um novo tema de pesquisa ou de um novo procedimento de investigação, que anos depois constataremos que terão sido definidores das características da psicologia brasileira - que, sendo assim, é feita na apropriação de um saber que lhe é estrangeiro. (Logo em seguida retomo esse ponto, para falar de alguns riscos com que nos defrontamos nesse momento; eles não são sem relação com os mesmos que enfrentamos hoje em dia e nos serão úteis para pensarmos a questão do impacto da internacionalização nos programas de pós-graduação.)

O que chama atenção nesse ponto é que, a rigor, nossos Programas de Pós-graduação sempre foram internacionalizados, nesse sentido de quase sempre estarmos voltados para o saber que nos chega dos países centrais e de adotarmos uma bibliografia maciçamente estrangeira. Mas não apenas nesse sentido: o GT2 do seminário "Horizontes”, ano passado, do qual fizeram parte Silvia Koller, Sebastião Almeida e Vera Paiva, além de mim, fez uma análise dos relatórios de 57 Programas de Pós-graduação na área, apresentados à CAPES, especialmente no quesito "Proposta do Programa”, e à época eu fiquei muito surpresa com a observação de que praticamente todos os Programas informam que têm intercâmbios com instituições estrangeiras, programas de estágios e outras participações em organismos internacionais.

As atividades incluídas com mais frequência foram: 1) a participação de alunos e professores em eventos internacionais; 2) a organização (conjunta ou não) de eventos internacionais; 3) visitas a centros e laboratórios estrangeiros; 4) visitas de professores estrangeiros aos Programas. Visitas essas que podiam ser pontuais (para palestras, oficinas, bancas) ou mais prolongadas (cursos). Fiquei surpresa também quando vimos que muitos Programas investiam na circulação 
de alunos e professores em estágios pós-doutorais nas universidades estrangeiras e alguns apresentavam grande preocupação com a publicação em periódicos internacionais... Vou voltar a esse ponto logo depois.

Mas ainda mais surpreendente foi constatar a gama de países com os quais havia algum tipo de intercâmbio: desde, é claro, as universidades norte-americanas, seguidas das francesas, mas também as alemãs, holandesas, espanholas, mexicanas e ainda uma enorme gama de universidades da América Latina, em especial com Colômbia, Argentina, Peru e Chile. E, agora eu entendo (dado ainda mais curioso que se destacou na análise que fizemos), as ações de internacionalização não dependiam de fatores como o número de docentes permanentes no Programa, ou do fato de Programas pertencerem ou não a uma dada universidade, ou de terem décadas ou apenas alguns anos de existência; nada dessas variáveis pareceram ser responsáveis pelas ações que visavam à internacionalização ou pela frequência com que foram mencionadas.

Esses dados de início nos surpreenderam, até porque vimos que as Fichas de Avaliação sequer valorizavam muito a informação. Foi só num segundo momento de reflexão que considerei que não havia com que eu ficar tão surpresa, não havia por que me surpreender: porque é do funcionamento mesmo do saber universitário, a tomada do referencial estrangeiro para o que desenvolvemos em nosso cotidiano, o mais corriqueiro. É da estrutura mesma que constitui o campo dos saberes essa tomada do que vem de fora. É então nesse sentido que eu estou considerando que a internacionalização exerce seu impacto na pós-graduação em psicologia no país, desde sempre.

Bem, mas há aqui outro dado, esse mais recente, tão recente quanto definitivo e marcante, que fala ainda de maneira mais radical da internacionalização dos saberes, que é a internet. Não temos nesse ponto um completo domínio sobre os efeitos que o acesso sem fronteiras a qualquer tipo de conhecimento irá trazer. Vemos com alguma nitidez que se finda a era do pesquisador-pensador em seu gabinete, com seus livros e suas interrogações, capturado por suas dúvidas e pelo seu trabalho a fundo perdido - justamente pesquisador-pensador que iria trazer sua contribuição para o saber universitário, esse que tomava um objeto para extrair dele um trabalho autoral e professoral.

Esse discurso universitário certamente, e isso já podemos ver, não encontra mais as mesmas condições de possibilidade que eram as determinantes anteriormente. (Como eu disse, ainda é cedo para recolhermos os efeitos do acesso infinito aos saberes.)

Certo rumor de que haverá uma superficialização e, portanto, uma desqualificação dos saberes ainda não se confirmou (agora mesmo há um best-seller chamado $O$ culto do amador); mas o que é importante aqui para nós, no entanto, é 
que nesse ponto mesmo, a internacionalização (de que vim falando anteriormente) se encontra com a informação sem fronteiras (que sequer se pode chamar de internacionalizada, que vem da internet).

Se encontra, no sentido de que em relação a ambas (a internacionalização $\boldsymbol{e}$ a informação da web) se trata da posição em que vai se colocar o pesquisador. Como ele vai se situar frente àquilo com que ele se depara. É nesse ponto também que podemos situar a escolha do que queremos para a produção do conhecimento no Brasil frente a esse contexto de internacionalização e globalização em que estamos mergulhados; é aqui que temos que nos colocar para examinar o que se trata de fazer com a psicologia.

É aqui também que podemos retomar um pouco do que foi levantado pelo GT sobre internacionalização no Seminário Horizontes, para recolocarmos algumas interrogações que persistem e que provavelmente insistirão ainda por algum tempo, na medida em que os indicadores nos quais temos confiança apresentam algumas impropriedades quando aplicados ao caso do Brasil e, mais especificamente, ao da Psicologia nacional.

Para lidar com essas questões vou tomar um caso que aparentemente nos vai levar a um desvio, mas que eu trago pelo valor que ele tem para mostrar as armadilhas em que caímos ao supormos estar fazendo parte de um também suposto conhecimento internacional uno/unificado pela referência a um método científico neutro e imparcial.

Trata-se do caso dos estudos higienistas de início do século na Europa. Não vou entrar em muitos detalhes, apenas o suficiente para desenvolver o meu argumento sobre os equívocos em que se pode incorrer nessa esfera da internacionalização...

Foi muito interessante ver a réplica feita no Brasil de estudos surgidos nas décadas de 1970 e 1980 na França e na Inglaterra que lá tomavam o higienismo como objeto de crítica. Nesses países, brevemente, podemos dizer que se fazia no início do século XX uma prédica a favor dos cuidados maternos à primeira infância. A taxa de mortalidade era muito alta, numa época em que era preciso ainda povoar com súditos britânicos ou com verdadeiros republicanos franceses as conquistas de além-mar. Criou-se então todo um saber que alterou significativamente as práticas ligadas aos cuidados materno-infantis. A qualidade do leite que era ingerido por mães e por filhos, por exemplo, desde essa época começou a ser controlada, pois se via nela uma das causas da saúde frágil de ambos. Progressivamente, as taxas de mortalidade começaram a baixar e a se manter em patamares mais aceitáveis. Bem, mas nesse mesmo tempo (e isso é o que os estudos realizados mais recentemente, nas décadas de 1970 e 1980, apontam) se instala 
uma nova moral com consequências visíveis para os hábitos e valores sociais. E esses estudos mais contemporâneos vão então criticar o controle que passa a ser exercido pelos dispositivos higienistas, sobretudo na conduta familiar. É muito curioso acompanhar as réplicas (desses estudos franceses e ingleses dos anos 1970 e 1980) feitas no Brasil. Porque abrindo os arquivos de nossas universidades (particularmente a Universidade do Brasil) encontramos aqui vários autores que, da mesma forma que os do movimento higienista na Europa de então (início do século XX), estavam preocupados com a higiene materno-infantil e defendem suas teses e escrevem seus artigos no assunto. E isso possibilita que façamos estudos similares, nas mesmas décadas de 1970/1980, aos estudos feitos na Europa. Ou seja, movimento higienista lá e cá (mais ou menos no início do século). E crítica ao movimento higienista lá e cá (nos anos 1970 e 1980): prova de que nas práticas discursivas que adotamos, no discurso universitário que nos orienta, podemos encontrar meios de fazer intercâmbios de ideias e não é descabido pensar em um higienista francês que tenha vindo falar aos brasileiros nem em um brasileiro que tenha ido estudar na Inglaterra com os higienistas de lá.

Porém, e esse é o porém que me interessa e do qual é necessário e inadiável que possamos ver os efeitos: de forma alguma, para nos mantermos apenas nesses dois itens, de forma alguma o leite aqui se tornou um leite de boa qualidade ou a taxa de mortalidade chegou perto da que era a dos países estrangeiros, na mesma época. Há quase um século separando as práticas discursivas (dos médicos, intelectuais, professores e pesquisadores higienistas brasileiros) das práticas que poderíamos, por falta de outra denominação, chamar de práticas institucionais. Há quase um século separando a melhora da qualidade do leite oferecido (quando oferecido às crianças) pelo país e quase um século para chegarmos às mesmas taxas de mortalidade infantil apresentadas pela França, por exemplo, como resultado lá da voga higienista.

Não quero extrair daí muito mais do que um ponto de interrogação ou um ponto para interrogação sobre o que pôde e o que pode estar em jogo uma vez que pensamos em internacionalização. Mesmo assim considero que estejamos frente a uma questão que nunca é suficientemente enfatizada: a de que o problema a que o pesquisador se endereça ao circunscrever o objetivo de sua pesquisa, a metodologia a que recorre para alcançá-lo, sem mencionar a leitura que faz dos resultados que encontra, ainda que apreendidos, todos, pela formalidade de um protocolo de pesquisa bem cuidado, não falam automaticamente do real que procuram circunscrever.

Por outro lado, no entanto, estamos frente a apenas um dos riscos que se corre quando pensamos nisso que é da estrutura dos saberes num país colonizado, de história recente. É, pois, um risco quase inerente à condição de um país 
que importa as ideias. Mas seria um tanto reducionista não vermos que há outras formas de apropriação ou de inserção e de relação com o saber e com a sua forma de inserção no âmbito internacional.

Mas justamente trata-se de saberes surgidos de uma prática que se dá no confronto cotidiano com dificuldades colocadas por circunstâncias bastante específicas do país e que requerem uma releitura, uma reinterpretação, ou uma escuta atenta de demandas que em geral vêm, literalmente até, do solo que as gera. Penso aqui por acaso nas pesquisas agrárias em particular, cujo avanço é notório em nosso país.

Mas, voltando à nossa área, uma área cuja característica mais evidente é a de ser uma somatória de inúmeros saberes e práticas que não comportam uma definição unívoca, temos que, por essa característica mesma, nos vemos em face de diferentes definições de psicologia que são resultado de diferentes definições de seu objeto de estudo, bem como se fazem acompanhar de métodos de pesquisa diversos. A psicologia pode ser entendida como um espaço de dispersão dos saberes: ora é o estudo do comportamento, ou o estudo das representações, ou ainda o estudo do sujeito (do inconsciente), ou da subjetividade, ou o estudo da cognição, ou o estudo do desenvolvimento humano, ou estudo das interações grupais e organizacionais etc., e cada objeto desses se deixa apreender de uma maneira diferente, isto é, exige procedimentos investigativos específicos.

Cada uma das subáreas terá interface com outras disciplinas que acabam por formar um espectro extremamente abrangente e complexo: há subáreas que fazem interface com a literatura, a linguística, a filosofia; há aquelas que estão próximas da sociologia, da antropologia, da ciência política; há outras próximas às ciências econômicas ou da administração; há aquelas que se enfileiram junto às ciências da saúde, às áreas mais exatas da fisiologia ou da biologia - as interfaces são, na verdade, incontáveis. É levando em conta a multiplicidade de pontos de referência em que a psicologia se apoia que temos que nos interrogar sobre a forma de internacionalização que cabe em cada saber dos que aí se configuram.

E é aí que as ações de internacionalização que mencionei anteriormente vêm cobrir as necessidades de cada subárea e é importante que esses esforços sejam sistematizados, comparados, quanto a suas consequências para a formação e para o exercício da pesquisa e, certamente, avaliados em seus efeitos para o avanço do trabalho em cada subárea. A distribuição de recursos se dará então por relação à avaliação e servirá para incentivar os projetos e pesquisa conjuntos, as missões de trabalho visando à estada de professores brasileiros em universidades estrangeiras e a de pesquisadores dessas universidades nos Programas brasileiros; trata-se também de financiar a ida desses pesquisadores para estágios pós-doutorais, bem como a dos discentes em doutorados-sanduíches, sempre no 
âmbito dos acordos bilaterais. A vinda de docentes e pesquisadores, bem como a de doutorandos do exterior, para participarem das pesquisas desenvolvidas nas universidades nacionais é outra modalidade a ser encorajada, ainda que nem sempre terá que ser financiada, obviamente, com os recursos brasileiros. Essas trocas então visariam à inserção das pós-graduações brasileiras no contexto internacional e não mais ocorreriam em mão única, do exterior para o Brasil, mas contariam com o efetivo intercâmbio de conhecimento entre diferentes grupos de pesquisa.

Não há dúvida que nesse exato momento se coloca a questão da publicação - isto é, a questão da escrita: forma de fixação de todas as ações e de todos os empreendimentos que fazem com que o país esteja no mundo. Não há dúvida que essa seja a questão mais importante nesse universo de textos que circulam e fazem circular as palavras que vêm de um e de outro canto. No entanto, creio que exista uma grande diferença entre a inscrição do que é feito, o seu tornar o que é feito público, e a obrigatoriedade de que a veiculação (essa que pode fazer com que o que é feito esteja no mundo) seja feita de uma maneira única e específica.

E, para bons entendedores, é suficiente dizer que certamente não estou defendendo que os veículos não prestem conta de seus cuidados para que a veiculação seja a de melhor qualidade e a mais pública que tiver que ser. No entanto, não há por que confundirmos internacionalização da produção com americanização da produção.

A meu ver, temos aqui um tópico sobre o qual não pudemos avançar no Seminário Horizontes e que, como disse anteriormente, ainda levaremos algum tempo para avaliá-lo, assim como deve demorar a avaliação das consequências de nossas avaliações: por isso acredito que possamos retomar mais uma vez os pontos lá recenseados.

Apesar das várias iniciativas no sentido de adaptar os padrões de avaliação da produção intelectual, de maneira a reconhecer e incluir as especificidades da área, não há como negar que as subáreas da psicologia, cujas técnicas de pesquisa e registros de resultados mais pretendem se aproximar das ciências exatas, são as que mais publicam nos veículos que seguem os ditames da bibliometria americana. E certamente os programas dessas subáreas são consequentemente tidos como de excelência.

Enquanto acreditarmos que há uma única forma de produzir conhecimento e, mais ainda, que o conhecimento assim produzido é a única forma de saber possível, ou mais ainda, que o saber possível é o saber positivado, mensurável, quantificável, logicizado, todo o saber que transgredir essa regra será considerado um saber menor. E, no entanto, há saber para além da positivação, e ele tem efei- 
tos bastante palpáveis quando se olha pela perspectiva dos objetos/sujeitos mesmos, a quem esses saberes se dirigem.

Há nesse sentido inclusive a intenção, que é uma boa intenção, de que se publiquem revistas brasileiras em inglês, língua que é tida por muitos como a que traz em si a linguagem da ciência. Sabemos, no entanto, que a ciência, a verdadeira, opera com letras. E não depende do idioma que a veicula. E, passando para um plano mais prosaico, o que vemos acontecer é que há diversas subáreas da psicologia que não sofrem qualquer influência anglo-saxã. Se, como admitimos anteriormente, nosso conhecimento é um conhecimento, desde o início, internacionalizado, há subáreas inteiras cujas fontes não são norte-americanas.

Há ainda outras situações, como, por exemplo, subáreas que até dependem de um conhecimento em inglês, importam muito do conhecimento americano, mas cuja natureza ou objetivo faz com que não tenha sentido a veiculação do seu produto final em outra língua que não o português. Pensamos particularmente em subáreas ligadas à saúde, em que o idioma em que interessa publicar, onde realmente os esforços de pesquisa apresentarão resultados de destacado mérito (muitas vezes para manter em funcionamento projetos cruciais para a vida mesma de pessoas no país), o idioma dessas subáreas, não é o inglês. Vários Programas poderiam exigir de seus docentes que se esforcem para publicar nos veículos acadêmicos de língua inglesa, no entanto, estariam retirando tempo e investimento de ações que realmente atingem seus objetivos.

E é necessário ressaltar que tais projetos estão longe de se situarem em campos periféricos, de pequena relevância ou de pouco alcance para o avanço da pósgraduação em psicologia no país. Ao contrário, eles colocam para os docentes o desafio de desenvolver e estabelecer fórmulas que possam efetivamente ser sistematizadas em termos teóricos e conceituais rigorosos, para garantir a transmissão das experiências em que se implicam.

Da mesma maneira, há subáreas que simplesmente não contam com nenhum veículo em língua inglesa; tampouco elas são periféricas, ao contrário, são campos muitas vezes tradicionais e mesmo fundadores e representativos da pesquisa em psicologia - pensamos aqui particularmente na pesquisa universitária em várias áreas da psicologia clínica, em especial a da teoria da clínica psicanalítica.

Seja por qual motivo for, sendo irrelevante ou impossível para alguns programas publicar em inglês, torna-se certamente impossível também julgar se ele tem ou não reconhecida excelência através de sua produção internacionalizada.

Para finalizar, eu só quero repetir o que foi colocado no Seminário de Bento Gonçalves, onde afirmamos que a principal questão da área refere-se à dependência dos índices de internacionalização que são demandados, quase sempre, 
homogeneamente num universo inteiramente heterogêneo. Além disso, permanecem em aberto outras questões que em última instância precisam ser respondidas adequadamente: se as avaliações privilegiam um número grande de publicações dando-lhe um peso bem maior que aos outros índices de internacionalização; se quaisquer outros critérios de internacionalização são considerados insuficientes para medir o nível de internacionalização que, na verdade, teria que, necessariamente, ser representado por uma boa produção intelectual em veículos estrangeiros ou internacionais, de preferência em inglês; vale dizer, se a publicação vem no lugar de todas as outras ações em direção à internacionalização, por que nos dedicaríamos a examiná-la? Certamente só vale a pena olhar para outros índices de internacionalização dos Programas e de seus docentes-pesquisadores se eles tiverem um peso que os reconheça como trazendo benefícios para a pós-graduação em psicologia. Essas para mim são questões urgentes sobre as quais temos ainda muito a avançar.

Citação/Citation: Lo BIANCO, A.C. Da globalização inevitável à internacionalização desejável. Revista Latinoamericana de Psicopatologia Fundamental, São Paulo, v. 12, n. 3, p. 445-453, set. 2009.

Editor do artigo/Editor: Prof. Dr. Manoel Tosta Berlinck.

Recebido/Received: 3.6.2009 / 6.3.2009 Aceito/Accepted: 6.7.2009 / 7.6.2009

Copyright: @ 2009 Associação Universitária de Pesquisa em Psicopatologia Fundamental/ University Association for Research in Fundamental Psychopathology. Este é um artigo de livre acesso, que permite uso irrestrito, distribuição e reprodução em qualquer meio, desde que o autor e a fonte sejam citados/This is an open-access article, which permits unrestricted use, distribution, and reproduction in any medium, provided the original author and source are credited.

Financiamento/Funding: $\mathrm{O}$ autor declara não ter sido financiado ou apoiado/The author has no support or funding to report.

Conflito de interesses: $\mathrm{O}$ autor declara que não há conflito de interesses/The author declares that has no conflict of interest.

\section{Ana Carolina lo Bianco}

Professora do Programa de Pós-graduação em Teoria Piscanalítica da Universidade Federal do Rio de Janeiro - UFRJ (Rio de Janeiro, RJ, Brasil); psicanalista membro do Tempo Freudiano Associação Psicanalítica (Rio de Janeiro, RJ, Brasil).

Av. Pasteur, 250 - Praia Vermelha 22290-240 Rio de Janeiro, RJ, Brasil

e-mail: teoriapsi@psicologia.ufrj.br 